\title{
Description of a new phlebotomine species, Evandromyia gaucha sp. nov. (Diptera: Psychodidae: Phlebotominae), from Rio Grande do Sul, Brazil
}

\author{
José Dilermando Andrade Filho/ ${ }^{+}$, Getúlio Dornelles Souza*, Alda Lima Falcão
}

\begin{abstract}
Centro de Referência Nacional e Internacional para Flebotomíneos, Laboratório de Leishmanioses, Centro de Pesquisas René Rachou-Fiocruz, Av. Augusto de Lima 1715, 30190-002 Belo Horizonte, MG, Brasil *Secretaria Estadual de Saúde do Rio Grande do Sul, Fundação Estadual de Produção e Pesquisa em Saúde, Porto Alegre, RS, Brasil
\end{abstract}

The present paper describes a new phlebotomine species, Evandromyia gaucha sp. nov., based on seven females found in the municipality of Caçapava do Sul, state of Rio Grande do Sul, Brazil. The new species belong to rupicola series and differs from other sand flies of the genus Evandromyia due to the presence of a rounded spermatheca head with its size very close to that of the spermatheca body.

Key words: Evandromyia gaucha sp. nov. - Evandromyia s. str. - Aldamyia - leishmaniasis

Phlebotomine sand flies are Nematocera diptera, responsible for the maintenance of leishmaniasis transmission between animals, including humans. In Brazil, the disease causes a range of public health damages and it has been the focus of investigations aimed to reveal its epidemiological aspects, including its vectors.

The phlebotomine fauna is little studied in the state of Rio Grande do Sul, where a number of 19 species are known (Dias et al. 1997, Silva \& Grunewald 1999, Silva et al. 2004). Insect collections carried out in the last four years in some municipalities of this state by one of us (GD Souza) revealed three more phlebotomine species, Evandromyia cortelezzii (Brèthes, 1923), Evandromyia edwardsi (Mangabeira, 1941), and Lutzomyia gaminarai (Cordero, Vogelsang \& Cossio, 1928). It is possible that this number does not represent the whole species diversity in the state, since few investigations on sand fly fauna have been reported in scientific literature.

In order to further knowledge on the sand fly fauna in Rio Grande do Sul, collections were performed in the municipality of Caçapava do Sul and among other species one was found to be a new phlebotomine sand fly.

\section{MATERIALS AND METHODS}

The sand fly specimens were collected with three CDC light traps in a riparian forest along the stream of Santa Bárbara, in the locality of 2nd district of Santa Bárbara, a rural zone in the municipality of Caçapava do Sul, state of Rio Grande do Sul, Brazil. Collections were undertaken in the periods between 4 and 6 January 2005 , and 4 and 8 January 2006, during $12 \mathrm{~h}$ (between 6 pm to $6 \mathrm{am})$. In the periods of insect captures, temperatures

Financial support: Capes, Secretaria de Vigilância em Saúde ${ }^{+}$Corresponding author: jandrade@ cpqrr.fiocruz.br

Received 23 March 2007

Accepted 20 June 2007 were measured and they ranged from $22^{\circ} \mathrm{C}$ to $30^{\circ} \mathrm{C}$ in 2005 , and from $15^{\circ} \mathrm{C}$ to $30^{\circ} \mathrm{C}$ in 2006 . After being prepared and mounted on glass slides using Berlese liquid, the material was sent to the National and International Reference Center for Phlebotomines of the Centro de Pesquisas René Rachou-Fundação Oswaldo Cruz, in Belo Horizonte, state of Minas Gerais, Brazil.

The new species was measured under light microscopy (Olympus $\mathrm{CH}-2$ ) adapted with a micrometer objective lens in light chamber (Olympus). Measurements were provided in micrometer and the terminology follows McAlpine (1981). The species was named Evandromyia gaucha sp. nov after the "gauchos", i.e. the people born in the state of Rio Grande do Sul.

\section{DESCRIPTION}

Evandromyia gaucha sp. nov (Figs 1-4)

Phlebotomine sand fly with a median size, 2576. Brown mesonotum and metanotum; light pronotum and pleura, except for the postnotum with pale brown katepisternum, katepimeron, and coxae.

Head - Measures: $405(446+15 ; \mathrm{n}=6)$ long and $315(333+21 ; \mathrm{n}=6)$ wide. Eyes: length $157(161+8$; $\mathrm{n}=5)$; width $83(94+5 ; \mathrm{n}=5)$. Clypeus $149(164+9$; $\mathrm{n}=6$ ) long. Antennae with simple ascoids not reaching the following segment. Antennal formula: AIII-AXV 2, AXVI 0. Flagellomere lengths: AIII = $281(301+15$; $\mathrm{n}=6), \mathrm{AIV}=116(121+8 ; \mathrm{n}=6), \mathrm{AV}=124(124+7$; $\mathrm{n}=6)$. AXV longer than AXVI $(\mathrm{n}=7)$. Papilla present on AIII, AV, and AXIII. Palpal formula: 1.4.2.3.5 $(\mathrm{n}=7)$. Length of the palpomeres: $\mathrm{P} 1=33(34+3 ; \mathrm{n}=6) ; \mathrm{P} 2=$ $143(154+7 ; \mathrm{n}=6) ; \mathrm{P} 3=154(169+7 ; \mathrm{n}=6) ; \mathrm{P} 4=$ $107(118+9 ; \mathrm{n}=6) ; \mathrm{P} 5=327(336+21 ; \mathrm{n}=5) . \mathrm{P} 5$ longer than P3 + P4 or P2 + P3 or P2 + P4. Newstead's spines inserted medially on palpomere 3 , also present on its apical third portion. Labrum-epipharynx 281 (296 $+16 ; n=6$ ). Maxilla: lacinia with approximately five teeth in a single longitudinal row. Labial suture united. Cibarium with four horizontal teeth; two groups of ap- 


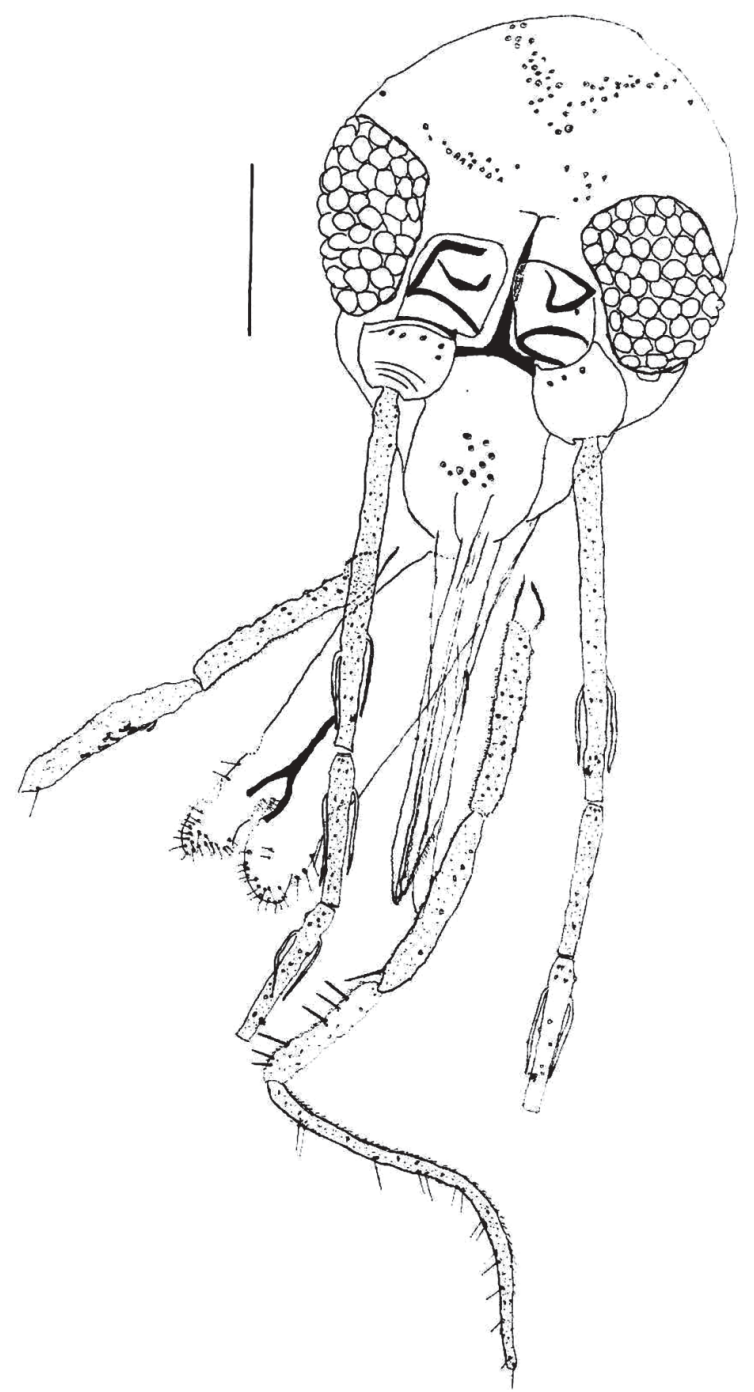

Fig. 1: Evandromyia gaucha sp. nov. (holotype female). Head, frontal view. $B a r=100 \mu \mathrm{m}$.

proximately 10 vertical teeth below of the outer horizontal teeth and two greater vertical teeth below the inner horizontal teeth. Pigment patch absent. Arch complete, but little pigment. Unarmed pharynx.

Cervix - Ventro-cervical sensillae present.

Thorax - Setae present on the anterior katepisternum margin. Pleura with three $(3-4 ; \mathrm{n}=6)$ proepimeral setae and $21(19-23 ; n=6)$ upper anepisternal setae. Wing: lenght $2.081(2.139+97 ; \mathrm{n}=5)$, maximum width 574 $(632+34 ; \mathrm{n}=5)$; main alar indices: alpha $495(516+$ $44 ; \mathrm{n}=6) ;$ beta $214(229+21 ; \mathrm{n}=6) ;$ gamma $293(294$ $+22 ; \mathrm{n}=6) ;$ delta $112(158+46 ; \mathrm{n}=6) ; \mathrm{R} 51.294$ $(1.360+75 ; n=6)$. Legs with no special features. Length of femur, tibia, tarsomere I and tarsomere II + III + IV + V: fore-legs $754(810+42 \mathrm{n}=6), 821(861+46 ; n=$ 6), $518(542+26 ; n=6), 675(718+31 ; n=6)$; midlegs $754(812+38 ; n=6), 979(1.063+47 ; n=6)$,

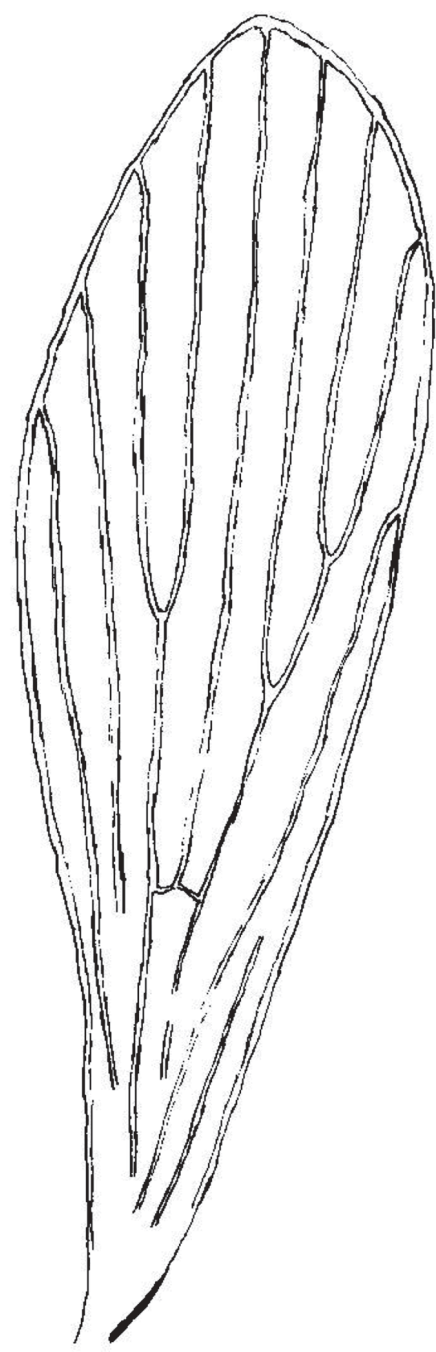

Fig. 2: Evandromyia gaucha sp. nov. (holotype female). Wing. Bar $=50 \mu \mathrm{m}$.

$574(621+30 ; \mathrm{n}=6), 698(747+38 ; \mathrm{n}=6) ;$ hind-legs $821(887+59 ; \mathrm{n}=5), 1.260(1.386+108 ; \mathrm{n}=5), 664$ $(741+32 ; n=5), 743(804+43 ; n=4)$.

Abdomen - Cercus with no special features. Setae on the 8th tergite absent. Spermatheca 52 long by 28 wide, with rounded body presenting little striations laterally; the head of spermatheca with 28 long by 25 wide, being also rounded and well developed with its measurements very similar to those of the body. Individual and common sperm ducts were not visualized, nor was the junction of the individual duct with the spermatheca.

Type-material - Holotype female collected with CDC light trap, in a riparian forest along the stream of Santa Bárbara, in the locality of II Distrito Santa Bárbara, a rural zone in the municipality of Caçapava do Sul, Rio Grande do Sul, Brazil on 8 January 2006 (Souza GD Col.). Two female paratypes with the same specifica- 


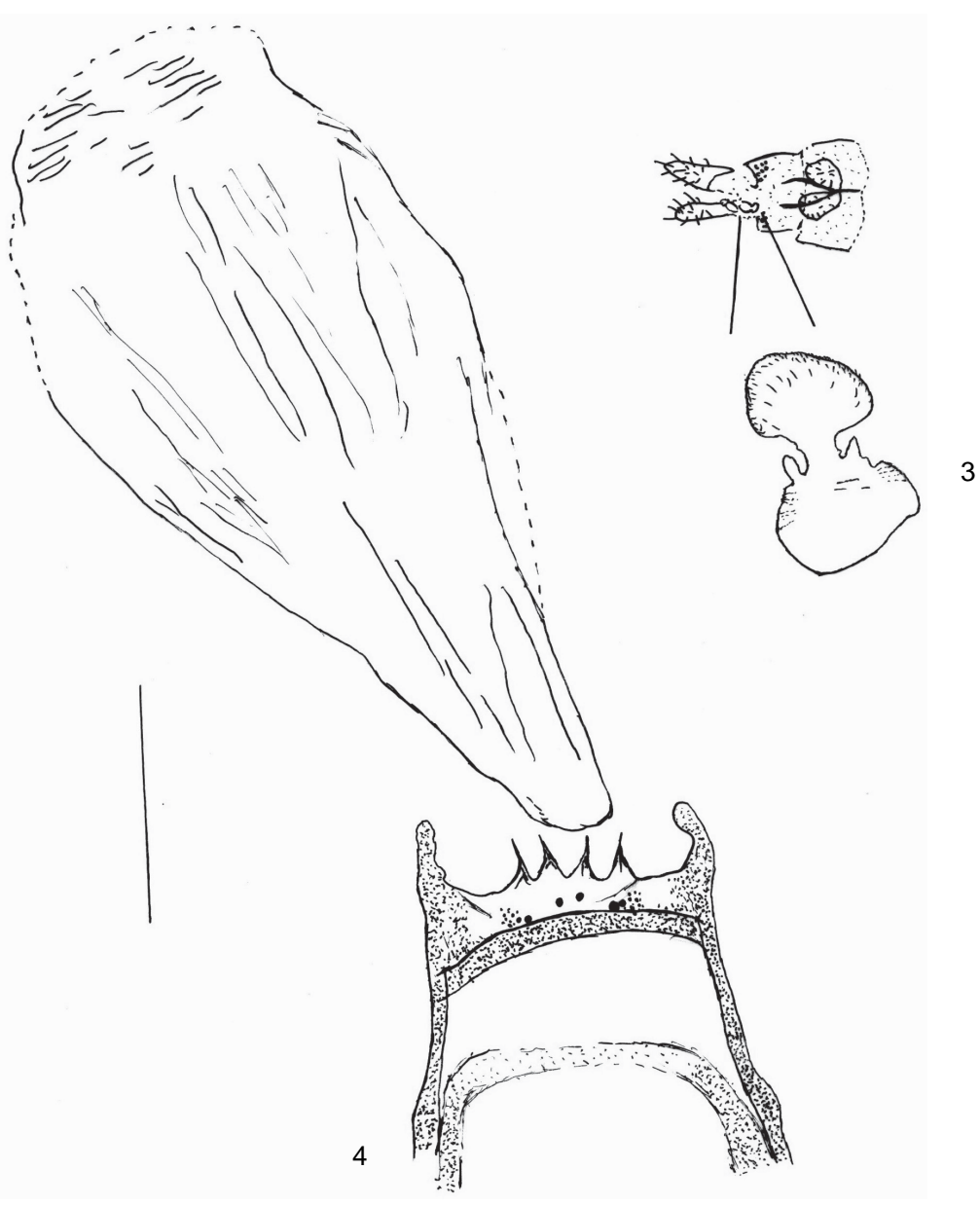

Figs. 3-4: Evandromyia gaucha sp. nov. (holotype female). 3: spermatheca; 4: pharynx and cibarium. Bar $=200 \mu \mathrm{m}$.

tions of the holotype; four female paratypes collected in the locality on 4 January 2005 . The material-type is deposited in the Phlebotomine Collection of the Centro de Pesquisas René Rachou-Fiocruz, Belo Horizonte, Brazil.

\section{TAXONOMIC DISCUSSION}

Among the species that occur in the state of Rio Grande do Sul, all are known by both male and female description with no taxonomic divergences when genders are associated and the description of the new species based only on female in the present article may be validated.

The presence of ventro-cervical sensillae, setae on the anterior katepisternum margin, papilla on the flagellomere AIII, AV, and AXIII are characteristic of the genus Evandromyia Mangabeira, 1941 (Galati 2003). This genus is divided into three subgenera: Evandromyia s. str., Aldamyia Galati, 1995 and Barrettomyia Martins \& Silva, 1968. Such separation may be based on differences found in the cibarium. In Aldamyia, the vertical teeth are laterally displayed, while in the other two subgenera, some teeth are located in the central region (Galati 2003, Braga-Miranda \& Galati 2005).
The new species shows two vertical teeth centrally located in the cibarium, which would make it similar to Barrettomyia and Evandromyia s. str. (rupicola series), mainly to Evandromyia correalimai (Martins, Coutinho \& Luz, 1970), which also presents highly transparent sperm ducts and occurs in the state of Rio Grande do Sul; however, the spermatheca is very different from that found in these two subgenera, and also from Aldamyia, whose spermatheca is apple-like shaped. E. (A.) termitophila with annulated spermathecae, is considered an exception of the subgenus; if the new species is included in subgenus Aldamyia, this would be the second exception regarding the spermatheca shape.

Based on what has been exposed and considering the fact that none of the spermatheca ducts could be visualized, we preferred not to include E. gaucha in any of the subgenera. Possibly, when a male specimen of this species is described, it can be clustered in one of the groups in the genus Evandromyia.

The separation of this species of the others Neotropical phlebotomine sand flies may be safely carried out through its spermatheca characterization. The pattern of 
the body-head set of spermatheca is unique within the subfamily Phlebotominae; furthermore, the spermatheca head size is very close to that of the spermatheca body.

\section{ACKNOWLEDGEMENTS}

To Mr Aristites Geraldo Lobato Araújo for the shelter and authorization of the collections in its property.

\section{REFERENCES}

Braga-Miranda LC, Galati EAB 2005. Description of the female of Evandromyia (Aldamyia) aldafalcaoae (Santos, Andrade-Filho \& Honer) (Diptera: Psychodidae, Phlebotominae). Neotrop Entomol 34: 331-336.

Dias ES, Falcão AL, Silva JE 1997. Notes on the sand fly fauna (Diptera: Psychodidae) in the state of Rio Grande do Sul, Brazil. Mem Inst Oswaldo Cruz 92: 329-332.
Galati EAB 2003. Classificação de Phlebotominae. In EF Rangel, R Lainson, Flebotomíneos do Brasil, Fiocruz, Rio de Janeiro, p. 23-51.

McAlpine JF 1981. Morphology and terminology - Adults. In JF McAlpine, BV Peterson, GE Shelwell, H J Teskey, JR Vockeroth, DM Wood, Manual of Nearctic Diptera, Research Branch Agriculture Canada, Ottawa, Monography 27, Vol. 1, p. 9-63.

Silva OS, Grunewald J 1999. Contribution to the sand fly fauna (Diptera: Phlebotominae) of Rio Grande do Sul, Brazil and Leishmania (Viannia) infections. Mem Inst Oswaldo Cruz. 94: 579-582.

Silva OS, Blazius RD, Romão PRT 2004. Flebotomíneos (Diptera: Psychodidae) coletados em galinheiro no Rio Grande do Sul, Brasil. Entomol Vect 11: 283-289. 